\title{
Impact of Excess Body Weight on Health-Related Quality of Life Among Adults in Lebanon
}

\author{
Linda Abou Abbas \\ $\mathrm{PhD}$, Neuroscience research center, Faculty of medical sciences, \\ Lebanese univsersity, Lebanon \\ Rana El Haidari
}

PhD Candidate, University of Bourgogne, Franche-Comté, France

Khodor Haidar Hassan

MD, PhD, Professor, Faculty of Public Health.Hadath.

Lebanese University. Lebanon.

\section{Abstract}

The objective of this study is to evaluate the impact of excess body weight on Health-Related Quality of Life (HRQoL). A convenience sample of 320 adults was recruited from different health centers in Lebanon. Body mass index $\left(\mathrm{kg} / \mathrm{m}^{2}\right)$ was calculated based on measured weight and height. Participants were divided into three groups: normal-weight (18.5-24.9), overweight (25.0-29.9) and obese ( $\geq 30.0)$. HRQoL was assessed using the Short-Form health survey questionnaire (SF-36). The eight scales as well as the physical (PCS-36) and mental (MCS-36) component summary measures of the SF-36 were calculated and compared statistically among the three groups. The impact of Body Mass Index (BMI) on HRQoL was also examined through linear regressions, adjusting for sociodemographics, health behaviors and presence of chronic diseases. The results show that overweight and obese men reported reduced HRQoL on all physical scales, while overweight/obese women reported impairments on only two subscales: bodily pain and general health perceptions. PCS-36 showed lower scores in the obese and overweight subjects than the reference group. With regard to mental well-being, obese men and women displayed lower scores on vitality, social functioning and mental health subscales compared to the normalweight group. Additionally, MCS-36 showed lower scores in obese subjects. Results from linear regressions revealed significant negative correlations between BMI and both PCS-36 and MCS-36. In conclusion, overweight adults experience significantly worse physical HRQoL, while obese adults suffer from reduced physical and mental HRQoL. This highlights the 
importance of development and implementation of effective prevention strategies to improve HRQoL among adults with overweight and obesity.

Keywords: Excess body weight, Health related quality of life, SF-36, Body Mass Index; Adults

\section{Introduction}

Over the past few decades, health perception and quality of life in patients with chronic diseases have gained increasing interest for both researchers and decision makers [1-3]. The escalating prevalence of chronic diseases and the increase in human life expectancy [4] have imposed a new approach in evaluating health. This is based on looking beyond determinants of death and morbidity to examine the impact of health status on an individual's quality of life. This approach is referred to as "health-related quality of life (HRQoL)" [5].

Although there is no universally accepted definition for the term "quality of life", there is agreement in the literature that HRQoL is a multidimensional construct that encompasses five generic health concepts: physical health, mental health, social functioning, role functioning, and general health perceptions [6]. Subjective measures of HRQoL have been widely used as indicators of health status in population surveys [7], and in routine clinical practice [8-10]. These measures are now recognized as important components of public health surveillance [11] and as valid outcomes in clinical trials $[11,12]$. As a result, HRQoL is considered an important tool in the assessment of the impact of diseases on patients as perceived by the patients themselves.

In the context of chronic diseases, obesity is considered a complex prevalent condition emerging as one of the major factors in increasing morbidity and mortality, [13] as well as decreasing life expectancy [14] and as such has dramatic influence on the overall HRQoL [15, 16]. Indeed, previous studies provide evidence to support a strong relationship between excess body weight and poor physical HRQoL [17-20]. With regard to mental HRQoL, findings were inconsistent. Whilst some studies have reported that obesity is associated with significantly impaired mental HRQoL [16, 18], others have found insignificant or no differences on psychological functioning in obese individuals when compared to their normal weight counterparts $[17,19,21,22]$. As these findings of the impact of excess weight on HRQoL are limited to studies from western populations and given the increasingly alarming rates of overweightness and obesity among adults in the Middle East [23], it is worth investigating the relationship between these two constructs in these populations. Better knowledge on this issue can help professionals in developing and 
implementing effective health care management plan for adults suffering from excess body weight.

Giving this background, the aim of the present study is to evaluate the impact of excess body weight on HRQoL among adults in Lebanon. It is hypothesized that Lebanese adults with excess body weight have lower scores on HRQoL domains as compared to their normal weight counterparts.

\section{Materials and Methods Study design and participants}

This is a cross-sectional descriptive study targeting Lebanese adults (age $\geq 18$ years). Participants were recruited through convenience sampling from different health centers. Lebanese adults of both genders aged 18 years and above were included. Exclusion criteria were as follows: pregnant or lactating women, individuals undergoing current weight loss treatment or those who had accomplished a significant weight loss during the last six months.

The study was designed to detect a difference in the mean scores of the SF-36 domains and its summary components across BMI categories (normal-weight, overweight and obese subjects). Sample size was computed on the basis of results obtained from previous study [20] with an assumed two-sided significance of $5 \%$ and a power of $80 \%$. This produced a total minimal sample size of 192 participants (64 subjects in each group). Sample size calculations were performed using G-Power version 3.1.9.2 Kiel, Germany.

\section{Study procedures}

Due to the observational nature of the study, the Institutional Review Board (IRB) of our university waived the need for an official approval, however, researchers and field workers conducted the study according to the research ethics guidelines laid down in the Declaration of Helsinki [24].

Participants were informed of the purpose of the study upon recruitment. Prior to their participation in this study, all individuals gave their written informed consent. Privacy and confidentiality were respected.

Data was collected using a self-administered questionnaire including information about socio-demographic characteristics (age, gender, marital status, family income per month, and levels of education), health behaviors (current smoking status and physical activity), presence of chronic diseases (including the presence of hypertension, diabetes Mellitus, coronary heart disease, cancer, and mental illness), quality of life and anthropometric measures. 


\section{Study Measurements}

\section{Health-Related Quality of Life (HRQoL)}

HRQoL was assessed using the Short Form 36-item Health Survey (SF-36) [25]. An Arabic version of the Short Form 36-item Health Survey (SF-36) which was validated and culturally adapted for the Lebanese population was used in our study [26].

SF-36 is a valid and reliable generic measure that consists of 36 items measuring eight health domains: physical functioning (PF), role physical (RP), bodily pain (BP), general health (GH), vitality (VT), social functioning (SF), role emotional (RE) and mental health $(\mathrm{MH})$. For each domain, item scores are coded, summed, and transformed to a scale from 0 to 100 with higher scores indicating better functioning or better health status. The eight dimensions of SF-36 are grouped into two summary measures: the "Physical Component Summary (PCS-36)" which includes mainly the scales related to physical health (PF, RP, BP, and GH) and the "Mental Component Summary (MCS-36)" which encompasses mainly the scales related to mental wellbeing (VT, SF, RE and MH). PCS-36 and MCS-36 are scored using US norm-based methods where the mean is set to 50 and the standard deviation (SD) to 10 [27]. A between-groups difference in score of 5 points on any one subscale is generally considered as clinically significant [28].

\section{Anthropometric measures}

Weight and height were measured by interviewers using a calibrated balance and a stadiometer (without shoes). BMI was calculated as weight in kilograms divided by height in metres squared. Consistent with the definitions set forth by the World Health Organization (WHO), students were grouped into three categories: 'normal-weight' (BMI $18.5-24.9 \mathrm{~kg} / \mathrm{m}^{2}$ ) as a reference group, 'overweight' (BMI $25.0-29.9 \mathrm{~kg} / \mathrm{m}^{2}$ ) and 'obese' (BMI $\geq 30 \mathrm{~kg} / \mathrm{m}^{2}$ ) [29].

\section{Statistical Analysis}

Data were entered and analyzed using the statistical software SPSS (Statistical Package for Social Sciences), version 22.0. Descriptive statistics were reported using means and standard deviations (SD) for continuous variables and frequency with percentages for categorical variables. As the HRQoL may differ between males and females, all the analyses were stratified by gender. Baseline characteristics were compared using chisquared test or Fischer Exact (when expected values were less than 5) for categorical variables and student $t$-test for continuous variables. Mean scores of the SF-36 domains and its component summary measures (PCS-36 and MCS-36) were compared among the three categories of BMI (normalweight, overweight and obesity) by the analysis of variance (ANOVA) test 
or the Kruskal-Wallis test, as appropriate. Bonferroni correction or MannWhitney $U$ test on post hoc analysis was used for pairwise comparison. Pearson or Spearman correlation coefficients were used to assess simple correlations between the SF-36 subscales and summary component measures and BMI. To further investigate the relationship between HRQoL and BMI, multiple linear regression analyses adjusted for age, marital status, level of education, smoking status, physical activity and presence of chronic diseases were performed with PCS-36 and MCS-36 as dependent variables. All statistical tests were two-sided, and the significant level was set at 0.05.

\section{Results}

Table 1 displays the baseline characteristics of the entire study sample and according to gender. Our sample consisted of 320 adults of which $61 \%$ were females. The mean age of the total sample was 27.7 years (ranging from 18 to 50 years). More than half $(57.5 \%)$ of our population consisted of single adults, the majority $(85.6 \%)$ had university or higher level of education, $9.3 \%$ of the participants were smokers and $7.3 \%$ suffered from chronic diseases.

The sample was either normal-weight $(32.1 \%)$, overweight $(37.2 \%)$ or obese $(30.8 \%)$ by design. Age, marital status, family income per month and presence of chronic diseases did not show any statistical significant differences between males and females. However, male participants were less educated, more engaged in physical activity, more likely to be current smokers and less likely to be overweight or obese compared to females.

In table 2, mean scores for the eight subscales and the two summary components of SF-36 across BMI categories and according to gender are displayed. As shown, overweight and obese men rated their health worse than the normal weight group on all the physical health subscales (PF, RP, $\mathrm{BP}$, and $\mathrm{GH}$ ), while overweight and obese women claimed reduced HRQOL on only two subscales (BP and GH). Concerning PCS-36, overweight/obese subjects of both genders reported significantly lower scores than the normal weight (P-value for post-hoc tests $<0.001$ ).

Of the four domains mainly related to mental well-being, obese men and women displayed lower scores than the refernce group on VT, SF and $\mathrm{MH}$, while no significant difference was found for RE subscale. Concerning overweight subjects, women reported lower scores for VT and SF, while only SF subscale was affected in men. With regard to MCS-36, obese subjects showed lower scores than the normal weight group (post-hoc test, pvalue 0.003 and 0.012 for men and women respectively).

A correlation analysis was then performed to evaluate the association between BMI, and SF-36 subscales and the component summary scores (Table 3). For men, a negative association was found on all subscales of the 
SF-36 except for RE, while for women PF, RP and RE did not show any significant correlations with BMI (P-value >0.05). Additionally, a significant negative correlation was found between the two component summary measures (PCS-36 and MCS-36) and BMI for both males and females.

Table 4 illustrates the unadjusted and adjusted effects of BMI on both PCS-36 and MCS-36. Results from simple regressions show that scores on both measures decrease with increasing BMI. In multiple linear regression analysis, with adjustments for age, marital status, level of education, smoking status, physical activity and presence of chronic diseases, the negative association between BMI and both PCS-36 and MCS-36 remained statistically significant for both males and females.

Table1. Baseline demographic and clinical characteristics of the study population by gender

\begin{tabular}{|c|c|c|c|c|}
\hline Characteristics & $\begin{array}{c}\text { All } \\
\text { participants } \\
\mathrm{N}=320\end{array}$ & $\begin{array}{c}\text { Male } \\
\mathrm{n}=125(39 \%)\end{array}$ & $\begin{array}{c}\text { Female } \\
\mathrm{n}=195 \\
(61 \%)\end{array}$ & P-value \\
\hline Age (Mean \pm SD) & $27.7 \pm 7.0$ & $27.8 \pm 7.0$ & $27.6 \pm 7.0$ & 0.7 \\
\hline Marital status n (\%) & & & & 0.8 \\
\hline Single & $184(57.5)$ & $71(56.8)$ & $113(57.9)$ & \\
\hline Married & $126(39.4)$ & $51(40.8)$ & $75(38.5)$ & \\
\hline Other $^{\dagger}$ & $10(3.1)$ & $3(2.4)$ & $7(3.6)$ & \\
\hline $\begin{array}{l}\text { Family income per month } \mathrm{n} \\
\qquad(\%)\end{array}$ & & & & 0.24 \\
\hline$<1,000,000$ & $62(19.5)$ & $19(15.3)$ & $43(22.2)$ & \\
\hline $1,000,000-2,000,000$ & $119(37.4)$ & $50(40.3)$ & $69(35.6)$ & \\
\hline $2,000,000-4,000,000$ & $93(29.2)$ & $41(33.1)$ & $52(26.8)$ & \\
\hline$\geq 4,000,000$ & $44(13.8)$ & $14(11.3)$ & $30(15.5)$ & \\
\hline Education level n (\%) & & & & 0.02 \\
\hline Secondary or less & $46(14.4)$ & $25(20.0)$ & $21(10.8)$ & \\
\hline University or higher & $274(85.6)$ & $100(80.0)$ & $174(89.2)$ & \\
\hline Cigarette smoking $\mathrm{n}(\%)$ & & & & $<0.001 *$ \\
\hline Non Smoker & $272(90.7)$ & $92(82.1)$ & $180(95.7)$ & \\
\hline Current smoker & $28(9.3)$ & 20(17.9) & $8(4.3)$ & \\
\hline Physical activity & & & & $<0.001 *$ \\
\hline No & $176(56.1)$ & $51(41.8)$ & $125(65.1)$ & \\
\hline Yes & $138(43.9)$ & $71(58.2)$ & $67(34.9)$ & \\
\hline Chronic disease $\mathrm{n}(\%)$ & & & & 0.34 \\
\hline No & 295(92.2) & $113(90.4)$ & 182(93.3) & \\
\hline Yes & $25(7.8)$ & $12(9.6)$ & $13(6.7)$ & \\
\hline BMI Category n (\%) & & & & $0.046^{*}$ \\
\hline $\begin{array}{l}\text { Normal weight (BMI 18.5- } \\
\left.24.9 \mathrm{Kg} / \mathrm{m}^{2}\right)\end{array}$ & $100(32.1)$ & $49(39.8)$ & $51(27.0)$ & \\
\hline $\begin{array}{l}\text { Overweight (BMI 25-29.9 } \\
\left.\qquad \mathrm{Kg} / \mathrm{m}^{2}\right)\end{array}$ & $116(37.2)$ & $38(30.9)$ & $78(41.3)$ & \\
\hline Obese $\left(\mathrm{BMI} \geq 30 \mathrm{Kg} / \mathrm{m}^{2}\right)$ & $96(30.8)$ & $36(29.3)$ & $60(31.7)$ & \\
\hline
\end{tabular}

Note: $\mathrm{n}$ frequency, $\%$ percentage; SD standard deviation; $\uparrow$ divorced or widowed; BMI Body mass index; *p-value $<0.05$ is considered statistically significant. 
Table 2. Mean SF-36 subscales scores for categories of BMI by gender

\begin{tabular}{|c|c|c|c|c|c|c|c|c|}
\hline \multirow[b]{2}{*}{ SF-36 } & \multicolumn{4}{|c|}{$\begin{array}{c}\text { Male } \\
(\mathrm{n}=125) \\
\end{array}$} & \multicolumn{4}{|c|}{$\begin{array}{l}\text { Female } \\
(\mathrm{n}=195)\end{array}$} \\
\hline & $\begin{array}{c}\text { Normal- } \\
\text { weight }\end{array}$ & Overweight & Obese & P-value* & $\begin{array}{c}\text { Normal } \\
\text { weight }\end{array}$ & Overweight & Obese & P-value* \\
\hline $\begin{array}{l}\text { Physical } \\
\text { function }\end{array}$ & $95.5(9.9)$ & $90.5(16.6)^{* *}$ & $\begin{array}{c}86.5(14.1) \\
* * *\end{array}$ & $<0.001 \dagger \dagger$ & $90.1(12.6)$ & $86.2(19.4)$ & $86.1(13.3)$ & $0.13+\dagger$ \\
\hline $\begin{array}{c}\text { Role } \\
\text { physical }\end{array}$ & $\begin{array}{c}91.8 \\
(23.6)\end{array}$ & $85.5(25.1)^{*}$ & $72.3(39.0)^{* *}$ & $0.01 \dagger \dagger$ & $87.5(26.9)$ & 76.9(33.9) & 79.1(32.0) & $0.15 \dagger \dagger$ \\
\hline $\begin{array}{l}\text { Bodily } \\
\text { pain }\end{array}$ & $89.4(14.1)$ & $67.8(25.5)^{* * *}$ & $61.3(22.3) * * *$ & $<0.001 \uparrow \dagger$ & $77.3(22.0)$ & $\begin{array}{c}56.9(24.6) \\
* * *\end{array}$ & $59.9(21.4)^{* * *}$ & $<0.001 \uparrow \dagger$ \\
\hline $\begin{array}{l}\text { General } \\
\text { health }\end{array}$ & 74.1(16.0) & $62.8(17.3)^{* *}$ & $55.9(18.5)^{* * *}$ & $<0.001 \uparrow$ & $69.6(17.4)$ & $61.3(19.1)^{*}$ & $57.4(19.8)^{* *}$ & $0.001 \uparrow$ \\
\hline Vitality & $66.9(13.4)$ & $57.9(21.8)$ & $53.5(17.6) * * *$ & $0.001 \dagger \dagger$ & $58.4(22.3)$ & $49.7(22.7)^{*}$ & $47.7(19.4)^{*}$ & $0.021 \dagger \dagger$ \\
\hline $\begin{array}{c}\text { Social } \\
\text { functioning }\end{array}$ & $84.5(15.5)$ & $73.3(24.8)^{*}$ & $\begin{array}{c}69.6(20.3) \\
* * *\end{array}$ & $0.002 \dagger \dagger$ & $75.9(22.6)$ & $64.7(27.1)^{*}$ & $61.3(27.0)^{* *}$ & $0.009 \dagger \dagger$ \\
\hline $\begin{array}{c}\text { Role } \\
\text { emotional }\end{array}$ & $87.1(29.5)$ & $74.8(35.5)$ & $82.0(36.5)$ & $0.08+\dagger$ & $75.9(38.0)$ & $71.6(37.9)$ & $69.7(37.8)$ & $0.55 \dagger \dagger$ \\
\hline $\begin{array}{l}\text { Mental } \\
\text { Health }\end{array}$ & 74.5(14.6) & $65.2(23.0)$ & $64.1(17.6) * *$ & $0.019 \dagger \dagger$ & $66.7(17.5)$ & $60.3(22.0)$ & $56.4(16.7)^{*}$ & $0.018 \dagger$ \\
\hline $\begin{array}{l}\text { Physical } \\
\text { Component } \\
\text { Summary } \\
\text { (PCS-36) }\end{array}$ & $57.1(6.9)$ & $50.6(8.3)^{* * *}$ & $46.4(10.2)^{* * *}$ & $0.002 \uparrow \dagger$ & $53.0(7.9)$ & $47.0(9.7)^{* * *}$ & $46.9(7.9)^{* *}$ & $<0.001 \dagger$ \\
\hline $\begin{array}{c}\text { Mental } \\
\text { Component } \\
\text { Summary } \\
\text { (MCS-36) }\end{array}$ & $56.8(8.1)$ & $50.6(12.8)$ & $50.4(9.4)^{* * *}$ & $0.003 \dagger \dagger$ & $51.6(11.1)$ & $47.2(12.0)$ & $45.5(9.7)^{*}$ & $0.012 \dagger$ \\
\hline
\end{tabular}

Note: Results are expressed as means and Standard Deviations.

Abbreviation: SF-36, Short-Form-36 Health Survey, PCS-36: Physical Component Summary of the SF-36; MCS-36: Mental Component Summary of the SF-36; PCS and MCS are standardized with a mean of 50 and a standard deviation of 10 .

All the tests are scored from 0-100 with higher scores representing better functioning or better health status.

*Differences between BMI categories were assessed using ANOVA or Kruskal-Wallis test.

$\dagger$ ANOVA tests, followed by Bonferroni's adjustment as post hoc analysis for pairwise comparison.

$\dagger \dagger$ Kruskal-Wallis tests, followed by repeated Mann-Whitney tests as post hoc analysis for pairwise comparison.

$* \mathrm{P}<0.05$ compared with the normal-weight group $\left(18.5-24.9 \mathrm{~kg} / \mathrm{m}^{2}\right)$.

$* * \mathrm{P}<0.01$ compared with the normal-weight group $\left(18.5-24.9 \mathrm{~kg} / \mathrm{m}^{2}\right)$.

$* * * \mathrm{P}<0.001$ compared with the normal-weight group $\left(18.5-24.9 \mathrm{~kg} / \mathrm{m}^{2}\right)$. 
Table 3 Correlations between BMI and SF-36 subscales and summary components scores

\begin{tabular}{ccccc}
\hline & \multicolumn{2}{c}{$\begin{array}{c}\text { Male } \\
(\mathrm{n}=125)\end{array}$} & \multicolumn{2}{c}{$\begin{array}{c}\text { Female } \\
(\mathrm{n}=195)\end{array}$} \\
\hline SF-36 & BMI & P-value & BMI & P-value \\
\hline Physical function (PF) & -0.45 & $<0.001 \dagger$ & -0.13 & $0.11 \dagger$ \\
Role physical (RP) & -0.25 & $0.005 \dagger$ & -0.09 & $0.23 \dagger$ \\
Bodily pain (BP) & -0.56 & $<0.001 \dagger$ & -0.28 & $<0.001 \dagger \dagger$ \\
General health (GH) & -0.43 & $<0.001 \dagger$ & -0.24 & $<0.001 \dagger$ \\
Vitality (VT) & -0.38 & $<0.001 \dagger$ & -0.20 & $0.005 \dagger$ \\
Social functioning (SF) & -0.35 & $<0.001 \dagger$ & -0.17 & $0.016 \dagger \dagger$ \\
Role emotional (RE) & -0.07 & 0.41 & -0.11 & $0.12 \dagger$ \\
Mental health (MH) & -0.25 & $0.006 \dagger$ & -0.20 & $0.005 \dagger$ \\
Physical Component Summary & -0.56 & $<0.001 \dagger$ & -0.20 & $0.005 \dagger \dagger$ \\
(PCS-36) & & & & $0.02 \dagger \dagger$ \\
Mental Component Summary & -0.32 & $<0.001 \dagger$ & -0.17 & \\
(MCS-36) & & & & \\
\hline
\end{tabular}

Note: Results are expressed as correlation coefficients.

Abbreviation: SF-36, Short-Form-36 Health Survey, $n$ frequency

$\dagger$ Spearman test, $\dagger \dagger$ Pearson test, $\mathrm{P}$-value $<0.05$ is considered significant.

Table 4 Linear regression analyses of the association between BMI and the SF-36 component summary measures (PCS-36 and MCS-36)

\begin{tabular}{|c|c|c|c|c|c|c|}
\hline & \multicolumn{3}{|c|}{ PCS-36 } & \multicolumn{3}{|c|}{ MCS-36 } \\
\hline & $\begin{array}{c}\text { Unstandardized } \\
\text { Beta }\end{array}$ & $\begin{array}{c}\text { Standardized } \\
\text { Beta }\end{array}$ & $\begin{array}{c}\text { P- } \\
\text { value* }\end{array}$ & $\begin{array}{c}\text { Unstandardized } \\
\text { Beta }\end{array}$ & $\begin{array}{c}\text { Standardized } \\
\text { Beta }\end{array}$ & $\begin{array}{c}\text { P- } \\
\text { value* }\end{array}$ \\
\hline $\begin{array}{c}\text { Male } \\
(\mathrm{n}=125) \\
\text { Model } 1\end{array}$ & & & & & & \\
\hline $\begin{array}{c}\text { BMI } \\
\text { Model } 2\end{array}$ & -0.88 & -0.50 & $<0.001$ & -0.66 & -0.34 & $<0.001$ \\
\hline BMI & -0.76 & -0.43 & $<0.001$ & -0.39 & -0.20 & 0.038 \\
\hline $\begin{array}{l}\text { Female } \\
(\mathrm{n}=195) \\
\text { Model } 1\end{array}$ & & & & & & \\
\hline $\begin{array}{c}\text { BMI } \\
\text { Model } 2\end{array}$ & -0.35 & -0.20 & 0.005 & -0.36 & -0.17 & 0.022 \\
\hline BMI & -0.39 & -0.22 & 0.002 & -0.35 & -0.16 & 0.03 \\
\hline
\end{tabular}

Abbreviations: BMI Body Mass Index, SF-36 Short-Form-36 Health Survey, $n$ frequency,

PCS-36 Physical Component Summary of the Short-Form-36 Health Survey, MCS-36

Mental ComponenT Summary of the Short-Form-36 Health Survey .

*p-value $<0.05$ is considered statistically significant.

Model 1: no adjustment

Model 2: adjusted for socio-demographic variables (that is age, marital status (coded as single or other), level of education (coded as secondary or less/University or higher), health behaviors (that is smoking status (coded as no/yes), and physical activity (coded as no/yes)), and presence of chronic diseases (coded as no/yes), which included the presence of hypertension, diabetes Mellitus, coronary heart disease, cancer, and mental illness. 


\section{Discussion}

The aim of the present study is to evaluate the effect of excess body weight on HRQoL in a sample of Lebanese adults. Our findings highlighted the effect of overweightness and obesity on the physical as well as the mental aspect of HRQoL by gender. We found that overweight and obese adults of both gender experience significantly worse physical HRQoL, while only obese men and women claimed reduced mental HRQoL as compared to the normal weight group. Our results also showed that excess weight, as measured by BMI, was inversely correlated with both the SF-36 physical and mental health summary measures scores.

The results of our study support the existing literature by showing the considerably impairment of the physical HRQoL in overweight and obese adults [17-20]. When looking at the physically oriented domains, we found that overweight and obese men reported reduced HRQoL on all the scales (PF, RP, BP and GH), while overweight/obese women reported statistically significant impairments on only two scales namely BP and GH. Compared to normal weight, the PF and RP score deviations in overweight/obese women approached or exceeded what is considered meaningful change from the clinical perspective ( $\geq 5$ points) but these deviations did not reach statistical significance. The aggregate summary measure (PCS-36) revealed a clear poor physical HRQoL in both genders for overweight and obese adults. In fact, the majority of the studies that measured HRQoL using SF-36 found that being overweight or obese resulted in a statistically significant reduction in physical HRQoL summary measure component (PCS-36); this has been observed in representative samples of adults from both the United States [16] and the United Kingdom [30]. As would be expected, the high prevalence of comorbidities associated with bodily pain and the limited physical activities in the adult with excessive body weight could partly explain the impairment in the physical aspect of quality of life in this population.

Our analyses show that the results of the mental aspect of HRQoL differ strongly between overweight and obesity. Among overweight subjects, women reported lower scores for VT and SF domains, while only SF subscale was affected in men. Negative effects were found in the mentally oriented domains (VT, SF and $\mathrm{MH}$ ) among obese participants. The aggregate summary measure (MCS-36) revealed impairment in the mental health aspect of obese men and women, whereas no differences in mental health HRQoL were found in overweight compared to normal weight. In fact, several potential biological and psychological mechanisms influencing the course of the association between obesity and mental health have been addressed in the published literature $[31,32]$. Obesity may be linked to poor psychological health through biological pathways by the activation of 
systemic inflammation [33] and the dysregulation of the hypothalamicpituitary- adrenal (HPA) axis [34].

In our sample, an inverse relationship between BMI and both PCS-36 and MCS-36 was found suggesting that increased BMI has a significant negative impact on physical as well as the mental aspects of HRQoL. Of note, along with previous report [35], we found that increased BMI was most prominently correlated with bodily pain particularly among males; this relationship should receive more attention in clinical care.

Our regression analysis provided further evidence for the negative relationship between excess body weight, as measured by BMI, and both PCS-36 and MCS-36 even after adjusting for potential confounders. Indeed, a substantial number of studies have examined the relationship between BMI and HRQoL using SF-36. A consistent finding across these studies has been the negative impact of BMI on the physical functioning and mental health summary components of the SF-36 [19, 36].

Strengths of the study include the use of a well-validated psychometric scale to screen for HRQoL (SF-36), the weight and height measurements of the participants, the consistency of the findings with other studies and the adjustment for several important covariates. However, the results of this study need to be considered in light of several methodological limitations. The relatively small sample size and the risk of selection bias due to the lack of randomization might have restricted the capacity to generalize our findings among the adult population. The study was also limited by its cross-sectional study design because causality or temporal relationship cannot be ascertained. For example, though it is possible that excess weight may affect HRQoL, it is also possible that impaired HRQoL may lead to gain excess weight. Longitudinal population studies would be extremely valuable to assess causal pathways between obesity and HRQoL and differences of certain sub-groups within the general population.

In conclusion, Lebanese adults with excessive body weight experience poor physical and mental health related to the quality of life. This highlights the importance of HRQoL assessment in the adult population with excess body weight. Strategies should be directed toward the development and implementation of effective prevention strategies and social support to improve HRQoL of overweight and obese adults.

\section{References:}

1. Donabedian, A., Evaluating the quality of medical care. 1966. Milbank Q, 2005. 83(4): p. 691-729.

2. Guyatt, G.H., D.H. Feeny, and D.L. Patrick, Measuring healthrelated quality of life. Ann Intern Med, 1993. 118(8): p. 622-9. 
3. Garratt, A., et al., Quality of life measurement: bibliographic study of patient assessed health outcome measures. Bmj, 2002. 324(7351).

4. van Oostrom, S.H., et al., Time Trends in Prevalence of Chronic Diseases and Multimorbidity Not Only due to Aging: Data from General Practices and Health Surveys. PLoS ONE, 2016. 11(8): p. e0160264.

5. Romero, M., D. Vivas-Consuelo, and N. Alvis-Guzman, Is Health Related Quality of Life (HRQoL) a valid indicator for health systems evaluation? SpringerPlus, 2013. 2(1): p. 664.

6. Ware, J.E., Jr., Standards for validating health measures: definition and content. J Chronic Dis, 1987. 40(6): p. 473-80.

7. Wang, R., et al., Impact of hypertension on health-related quality of life in a population-based study in Shanghai, China. Public Health, 2009. 123(8): p. 534-9.

8. Younossi, Z.M., et al., Development of a disease specific questionnaire to measure health related quality of life in patients with chronic liver disease. Gut, 1999. 45(2): p. 295-300.

9. Faden, R. and A. Leplege, Assessing quality of life. Moral implications for clinical practice. Med Care, 1992. 30(5 Suppl): p. MS166-75.

10. Fitzpatrick, R., et al., Quality of life measures in health care. I: Applications and issues in assessment. Bmj, 1992. 305(6861): p. 1074-7.

11. Testa, M.A. and D.C. Simonson, Assessment of quality-of-life outcomes. N Engl J Med, 1996. 334(13): p. 835-40.

12. Moriarty, D.G., M.M. Zack, and R. Kobau, The Centers for Disease Control and Prevention's Healthy Days Measures - Population tracking of perceived physical and mental health over time. Health and Quality of Life Outcomes, 2003. 1: p. 37-37.

13. Lenz, M., T. Richter, and I. Mühlhauser, The Morbidity and Mortality Associated With Overweight and Obesity in Adulthood: A Systematic Review. Deutsches Ärzteblatt International, 2009. 106(40): p. 641-648.

14. Olshansky, S.J., et al., A potential decline in life expectancy in the United States in the 21st century. N Engl J Med, 2005. 352(11): p. 1138-45.

15. Fontaine, K.R. and I. Barofsky, Obesity and health-related quality of life. Obes Rev, 2001. 2(3): p. 173-82.

16. Jia, H. and E.I. Lubetkin, The impact of obesity on health-related quality-of-life in the general adult US population. J Public Health, 2005. 27(2): p. 156-64. 
17. Huang, I.C., C. Frangakis, and A.W. Wu, The relationship of excess body weight and health-related quality of life: evidence from a population study in Taiwan. Int J Obes, 2006. 30(8): p. 1250-9.

18. Ford, E.S., et al., Self-reported body mass index and health-related quality of life: findings from the Behavioral Risk Factor Surveillance System. Obes Res, 2001. 9(1): p. 21-31.

19. Larsson, U., J. Karlsson, and M. Sullivan, Impact of overweight and obesity on health-related quality of life--a Swedish population study. Int J Obes Relat Metab Disord, 2002. 26(3): p. 417-24.

20. Giuli, C., et al., Correlates of perceived health related quality of life in obese, overweight and normal weight older adults: an observational study. BMC Public Health, 2014. 14(35): p. 14712458.

21. Han, T.S., et al., Quality of life in relation to overweight and body fat distribution. Am J Public Health, 1998. 88(12): p. 1814-20.

22. Busutil, R., et al., The impact of obesity on health-related quality of life in Spain. Health and Quality of Life Outcomes, 2017. 15: p. 197.

23. Motlagh, B., M. O'Donnell, and S. Yusuf, Prevalence of cardiovascular risk factors in the Middle East: a systematic review. Eur J Cardiovasc Prev Rehabil, 2009. 16(3): p. 268-80.

24. Williams, J.R., The Declaration of Helsinki and public health. Bull World Health Organ, 2008. 86(8): p. 650-2.

25. Ware, J.E., Jr. and C.D. Sherbourne, The MOS 36-item short-form health survey (SF-36). I. Conceptual framework and item selection. Med Care, 1992. 30(6): p. 473-83.

26. Sabbah, I., et al., Quality of life in rural and urban populations in Lebanon using SF-36 health survey. Health Qual Life Outcomes, 2003. 1(30): p. 1477-7525.

27. Jenkinson, C., Comparison of UK and US methods for weighting and scoring the SF-36 summary measures. J Public Health Med, 1999. 21(4): p. 372-6.

28. Ware, J., SF-36 health survey: Manual and inter-pretation guide. The Health Institute, New England Medical Center, Boston. 1997.

29. National Clinical Guideline, C., National Institute for Health and Clinical Excellence: Guidance, in Obesity: Identification, Assessment and Management of Overweight and Obesity in Children, Young People and Adults: Partial Update of CG432014, National Institute for Health and Care Excellence (UK)

30. Copyright (c) National Clinical Guideline Centre, 2014.: London.

31. Doll, H.A., S.E. Petersen, and S.L. Stewart-Brown, Obesity and physical and emotional well-being: associations between body mass 
index, chronic illness, and the physical and mental components of the SF-36 questionnaire. Obes Res, 2000. 8(2): p. 160-70.

32. Stunkard, A.J., M.S. Faith, and K.C. Allison, Depression and obesity. Biol Psychiatry, 2003. 54(3): p. 330-7.

33. Markowitz, S., M. Friedman, and S. Arent, Understanding the Relation Between Obesity and Depression: Causal Mechanisms and Implications for Treatment Clinical Psychology Science Practice 2008. 15: p. 1-20.

34. Shoelson, S.E., L. Herrero, and A. Naaz, Obesity, inflammation, and insulin resistance. Gastroenterology, 2007. 132(6): p. 2169-80.

35. Walker, B.R., Activation of the hypothalamic-pituitary-adrenal axis in obesity: cause or consequence? Growth Horm IGF Res, 2001. 11(5): p. S91-5.

36. Yancy, W.S., Jr., et al., Relationship between obesity and healthrelated quality of life in men. Obes Res, 2002. 10(10): p. 1057-64.

37. Castres, I., et al., Quality of Life and Obesity Class Relationships. Int J Sports Med, 2010. 31(11): p. 773-778. 